\title{
Mixing Thermodynamics of Edible Olive or Soybean Oils with Ketones (2-butanone, 3-pentanone and 4-methyl-2-pentanone) at Different Temperatures
}

\author{
Caroline Maia ${ }^{1}$, Rebecca S. Andrade ${ }^{2}$, Miguel Iglesias ${ }^{1}$, Juan Lanz $^{3}$, Cristina Gonzalez ${ }^{3}$ \\ ${ }^{1}$ Departamento de Engenharia Química, Universidade Federal da Bahia, Salvador, Brasil \\ ${ }^{2}$ CETENS, Universidade Federal do Recôncavo da Bahia, Feira de Santana, Brasil \\ ${ }^{3}$ Dpto. de Ingeniería Química. Facultad de Farmacia. Universidad del País Vasco, UPV/EHU. Apto. 450. Vitoria. (Spain) \\ E-mail: miguel.iglesias@ufba.br
}

Received 31 May 2020, Revised 18 August 2020, Accepted 1 October 2020

\begin{abstract}
This paper reports densities, refractive indices, excess molar volumes, and changes of refractive indices on mixing for (2-butanone, 3-pentanone and 4-methyl-2-pentanone) with vegetable oils (olive or soybean) at temperatures from 283.15 to 298.15 K. Parameters of analytical expressions which represent the composition dependences of excess and variation of magnitudes are reported. Values of physical properties were compared with the results obtained by different theoretical procedures (equations of stateand semiempirical mixing rules). A good agreement between the experimental and theoretical values both in magnitude and sign were obtained by these methods, despite the sharp non-ideality of the studied mixtures and the strong influence of temperature on the computed derived properties.
\end{abstract}

Keywords: Density; refractive index on mixing; derived properties; edible oil; ketone; model; temperature.

\section{Introduction}

Traditionally, fats and oils are used mainly for human food purposes, but increasingly their use into wide scope industrial applications as additives of fuels for internal combustion motors and direct energy generation, reflects the growing worldwide importance of these commodities. Into the edible oil processing, those components which may produce negative effects on the organoleptic matrix, stability or nutritional value, are removed into different stages, preserving potential chemical changes in the triacyglycerols profile. Solvent extraction (winterization) is a common refining operation in the processing of seeds, where oils are mixed with an organic solvent to optimize the yield and allow high-melting components to crystallize in this appropriate low-viscous media. This is one of the critical points into this industrial process in terms of consuming time and the necessary high volume decantation tanks. In one hand, winterizing process evolving solvents offers advantages in the area of phase separation producing faster and sharper solid fractions than those obtained by vacuum filtration but, on the other hand, due to its more expensive cost and enormous difficulty of finding an appropriate solvent, it is already less common into edible oils industry.

For chemical engineers to successfully execute conceptual design, plant operations, maintenance and final product studies, process modelling and experimental research on thermodynamic properties of mixtures of interest are performed. Food technology is not an exception, and knowledge of thermodynamic properties and phase equilibria of fatties and oils is of practical interest in the industrial manufacture of these products. In the last few years a considerable effort has been applied in the field of thermodynamic properties of oils related to process technology. Such properties are strongly dependent on the presence of double bounds, chain lengths, and isomeric structures of fatty acids and molecular characteristics of triglycerides in solvents. Despite these efforts a considerable lack of accuracy or thermodynamic consistency in some data in the open literature is observed resulting from the different origins of fatty substances and the complexity of their composition and structure. Open literature data are related mainly to physico-chemical properties of pure oils or fatty acids [1-18], and until now there are scarce information related to the thermodynamic behaviour of edible oil mixing systems in wide ranges of temperature or pressure. It is not always possible to obtain proper values, especially when concerned with complex mixtures at non-standard conditions. In the scope of investigating physical properties related to equipment design in edible oils industry and new environment friendly procedures of extraction and refining, as a continuation of previous studies, we present the temperature dependence of the density and refractive indexof ketones (butanone, 3-pentanone and 4-methyl-2-pentanone) + natural olive and soybean oil over the range from 283.15 to $298.15 \mathrm{~K}$ at atmospheric pressure, as a function of molar fraction.This work is a part of a wider project related to the study of phase equilibria and thermodynamics of mixtures of edible oils and organic solvents [19-31], in order to provide a better understanding concerning the factors which contribute to the special behaviour enclosing triglycerides into mixtures, and improve the stage of winterization of edible oil industry. The study is carried out at low temperatures because modern technologies in oil processing use cool techniques to improve the quality of seeds oils, avoiding thermal degradation and organoleptic modifications.

Different theoretical models were applied to analyse their capability in terms of estimation of the studied properties as a function of composition and temperature. For density estimation, a simplification of the Nasrifar- 
Moshfeghian liquid density correlation (MNM method) was applied, replacing the Mathias and Copeman temperaturedependent term with the original Soave-Redlich-Kwong equation of state (SRK EOS) temperature-dependent term $[32,33]$. This replacement has overcome the limitations in use for the original model, which were due to the Mathias and Copeman vapor pressure dependent parameters. The Heller equation [34] was modified to estimate the volumetric trend of these complex mixtures as a function or temperature, using a polynomic dependency on mass fraction. The Halvorsen [35] (a modified Rackettmodel[36, 37]) equation of state was also tested for the pure oils density estimation.

In what is referred to estimate the refractive indices on mixing, different semiempirical rules were applied, which are dependent on the pure values at the studied temperature and, of course, the mixture composition. The experimental refractive indices on mixing have been compared with those estimated by means LorentzLorenz, Dale-Gladstone, Eykman, Arago-Biot, Newton, Oster, Eyring-John, Weiner and Heller rules [31].A good agreement between the experimental and theoretical values both in magnitude and sign were obtained by these methods, despite the sharp nonideality of the studied mixtures and strong influence of temperature on the computed derived properties.

\section{Experimental}

Analytical grade 2-butanone, 3-pentanone and 4methyl-2-pentanone were obtained from Fluka with a purity of $>99 \%$. Refined olive oil was supplied by Koipe (Jaén, Spain) and soybean oil by Moyresa (Vizcaya, Spain). Edible oils were previously analysed to know its composition in fatty oils and other physicochemical characteristics. Acid value, saponification value, iodine value, peroxide value, and wetness and volatiles were measured, too. These values were analyzed following standard procedures [38] and the obtained values are presented in Table 1 . The fatty acid composition was analysed by means of a gas chromatograph Shimazdu 4B gas chromatograph equipped with a flame detector. Chromatographic technique and the chemical procedure for the separation of fatty acids were described in previous works [19,2324]. The uncertainty in mol\% for these results being better than $0.1 \%$. From this composition, the average molar mass of this oil has been computed in accordance to the following expression:

$$
\mathrm{M}_{\mathrm{oil}}=3\left(\sum_{\mathrm{i}=1}^{\mathrm{N}} \mathrm{x}_{\mathrm{i}} \mathrm{M}_{\mathrm{i}}\right)+2 \mathrm{M}_{\mathrm{CH}_{2}}+\mathrm{M}_{\mathrm{CH}}
$$

being $\mathrm{x}_{\mathrm{i}}$ the molar fraction and $\mathrm{M}_{\mathrm{i}}$ the molar mass of each fatty acid attending the concentration analysis (without a proton), $\mathrm{N}$ the number of fatty acid found by analysis and $\mathrm{M}_{\mathrm{CH}_{2} \text { and }} \mathrm{M}_{\mathrm{CH}}$ are the molar mass contributions of triacylglyceride molecule fraction. The variation in the composition due to different samples of oils affects mainly the mono and polyunsaturated fatty acids, the change in molar mass being lower than $\pm 1 \mathrm{gmol}^{-1}$. Molar mass of the fatty oils calculated by eq. 1 appear in Table 2, as well as disposable open literature data of the used solvents.Sample mixtures of the required compositions wereprepared by mass using a Salter ER-182A balance, taking precautions to prevent evaporation of solvents; the accuracy being within $\pm 5 \times 10^{-4} \mathrm{~g}$. The possible error in the mole fraction was estimated to be less than \pm 0.0002 .The densities were measured using an Anton Paar DMA-58 vibrating-tube densimeter with a resolution of $\pm 1 \times 10^{-5} \mathrm{~g} \cdot \mathrm{cm}^{-3}$. The densimeter was calibrated with water and air, using the corresponding density of the water at each temperature, and air density was calculated by the equation:

$$
\text { density }_{t, p}=\frac{0.0012930 \cdot \mathrm{P}}{1+0.00367 \cdot \mathrm{t}}
$$

where $\mathrm{t}$ is temperature $\left({ }^{\circ} \mathrm{C}\right)$ and $\mathrm{P}$ is pressure (atm), in accordance with vendor technical specifications. Refractive index on mixing was measured with an automatic refractometer Mettler RE50 with accuracy of $\pm 10^{-5}$. Temperatures were accurate to $\pm 1 \times 10^{-2} \mathrm{~K}$ by Peltier control system for both equipment. The technical description of experimental procedure can be found in earlier works, as indicated above.

Table 1. Fatty acids composition of the studied oils (\% mass) and other characteristics

\begin{tabular}{lll}
\hline \multicolumn{1}{c}{ Property } & \multicolumn{1}{c}{ Olive Oil } & \multicolumn{1}{c}{ Soybean Oil } \\
\hline Composition & 16.1 Palmitic; & 10.9 Palmitic; \\
& 1.1 Palmitoleic; & 0.1 Palmitoleic; \\
& 2.4 Stearic; & 4.5 Stearic; \\
& 73.3 Oleic; & 24.0 Oleic; \\
& 5.7 Linoleic; & 53.4 Linoleic; \\
& 1.4 Linolenic & 6.5 Linolenic; \\
& & 0.6 Behenic \\
Acid Value & 0.27 & 0.05 \\
Saponification Value & 189.6 & 191.5 \\
Iodine Value & 79.6 & 129.3 \\
Peroxide Value & 9.5 & 12.6 \\
Wetness and volatiles & 0.049 & 0.018 \\
\hline
\end{tabular}

Table 2 Molar mass, experimental values of density and refractive

\begin{tabular}{|c|c|c|c|c|c|}
\hline & $\begin{array}{l}\text { lar mass } \\
\left.\mathrm{mol}^{-1}\right)^{\mathrm{a}}\end{array}$ & $\begin{array}{l}\text { :nsity } \\
\text { Exp }\end{array}$ & $\begin{array}{l}\text { Density } \\
\text { Lit. }\end{array}$ & $\begin{array}{l}\text { stive Index } \\
\text { Exp }\end{array}$ & $\begin{array}{l}\text { active Index } \\
\text { Lit. }\end{array}$ \\
\hline none & 2.107 & 7994 & $0.7997^{b}$ & .37613 & $1.37685^{\mathrm{b}}$ \\
\hline anone & 6.133 & 8097 & $1.80945^{\mathrm{b}}$ & .38972 & $1.39002^{\mathrm{b}}$ \\
\hline $\begin{array}{l}\text { lyl-2- } \\
\text { one }\end{array}$ & 0.161 & 7961 & $0.7963^{b}$ & .39344 & L.39361 b \\
\hline Jil & 13.486 & 9088 & $\begin{array}{c}0.9092^{c} \\
0.909^{d}\end{array}$ & 46703 & $168-1.471^{f}$ \\
\hline an Oil & '6.266 & 9159 & $121-0.924^{\mathrm{e}}$ & .47260 & $66-1.470^{\mathrm{f} *}$ \\
\hline
\end{tabular}
index and literature data at $298.15 \mathrm{~K}$

\section{Data Processing}

The experimental measured properties (density and refractive index on mixing) were applied for calculation of excess molar volumes and changes of refractive indices on mixing using the following equation:

$$
\delta \mathrm{Q}=\mathrm{Q}-\sum_{\mathrm{i}=1}^{\mathrm{N}} \mathrm{x}_{\mathrm{i}} \mathrm{Q}_{\mathrm{i}}
$$

where $\mathrm{x}_{\mathrm{i}}$ is the mole fraction, $\mathrm{N}$ is the number of components, $\mathrm{Q}$ is the physical property of mixture (molar volume or refractive index on mixing) and $Q_{i}$ is the same property of the pure compound $i$ at the same temperature.

The experimental densities and the computed excess molar volumes of the mixtures are shown in Tables S1S6for all studied mixtures as Supplementary Data. Refractive indices and changes of refractive indices on mixing of the prepared mixtures are listed in Tables S7- 
S12. All these tables are gathered as supplementary material into Appendix. The derived properties (excess molar volumes and changes of refractive indices on mixing) were correlated as a function of composition at each temperature by means of a Redlich-Kister expansion:

$$
\delta Q_{i j}=x_{i} x_{j}\left(\sum_{p=0}^{m} a_{p}\left(x_{i}-x_{j}\right)\right)
$$

where $\delta \mathrm{Q}_{\mathrm{ij}}$ stands for the derived magnitude for the binary mixture, $a_{p}$ are the fitting parameters, $x_{i}$ and $x_{j}$ are the molar fractions of solvent and oil and $\mathrm{m}$ is the degree of the polynomial. The $a_{p}$ parameters were computed using a nonlinear Marquardt optimization algorithm. The fitting parameters and the root mean square deviation (eq. 5) are listed in Tables 3 and 4. The root mean square deviations were computed using eq. 5 , where $\mathrm{z}$ is the value of the property, and $\mathrm{n}_{\mathrm{DAT}}$ is the number of experimental data.

$$
\sigma=\left(\frac{\sum_{\mathrm{i}=1}^{\mathrm{n}_{\mathrm{DAT}}}\left(\mathrm{z}_{\text {exp }}-\mathrm{z}_{\text {pred }}\right)^{2}}{\mathrm{n}_{\mathrm{DAT}}}\right)^{1 / 2}
$$

These fitting parameters were used to calculate the solid surfaces in Figures 1-4. Figures 1-2 gather excess molar volumes of ketones + (olive or soybean) oil versus mole fraction of ketone as a function of temperature. Figures 3-4 show the changes of refractive indices on mixing of ketones + (olive or soybean) oil versus mole fraction of ketone as a function of temperature.

The excess volume and changes of refractive index on mixing are thermodynamic properties that measure the mixing deviation from the ideal behaviour, and could be understood as a manifestation of the new intermolecular forces established into mixture, and then, the geometric and energetic factors evolved into the accommodation process of all the enclosed components into mixture for a specific temperature and pressure. These variations will depend on the molecule size and shape (polar groups, intramolecular freedom degrees and structural geometry) and which type of mixing intermolecular interaction prevails. The studied edible oils are mainly triacylglycerides (more than 99\%), differing in terms of fatty acids nature and composition. The difference with shorter esters is that they present two different structures: a central polar axis built up by three ester groups (alcoxicarboxylate) and three long linear chains (saturated or unsaturated, attending to the different fatty acids). As a consequence of this structure, the molecule is strongly bulk, which means that there will empty spaces among the linear chains where relative smaller molecules of solvent could be introduced.The difference between both edible oils is in terms of kind and mass percent of fatty acids. Soybean oil shows a slightly higher composition of unsaturated fatty acids (see Table 1), which produce a sparse higher tolerance for the lighter ketones (see values of TablesS1-S6 at different temperatures and equimolar compositions) and then, a higher contractive tendency at any composition and temperature (compare Figures 1a-1c and the corresponding Figures 2a-2c). The ketone solvents have one oxygen atom and two lone electronic pairs hanging out in a very exposed position, both of which make it seemingly capable of hydrogen bonding or polar interacion. Except in rather unusual cases, the hydrogen atom has to be attached directly to the very electronegative element for hydrogen bond to take place.In all the studied mixtures, the excess molar volume shows more negative values when the temperature rises, which means that higher molecular kinetics makes easier intermolecular interactions and then, a contractive trend when temperature rises.

The trend into soybean oil mixtures is clearly of contractive character, this tendency rising for higher temperatures and molar mass of the ketone solvent (with minima of excess molar volume at equimolar composition, approximately).The mixtures (2-butanone or 3-pentanone) + olive oil gather clear expansive trend at the lowest temperatures evolving to a clear sigmoid profile for rising temperatures. As expected, the negative values are observed at low ketone compositions (see Figures 1a and 1b).The progress diminution of the positive excess molar volumes in these mixtures should be interpreted as a consequence of better packing of these short ketones among triglyceride molecules by faster molecular kinetics when temperature rises. The different trend observed for the solvent 4-methyl2-pentanone into olive oil should be produced by its bulkier geometry and higher polarization profile.These facts are reflected in terms of change of refractive indices on mixing as positive deviations from ideality, pointing out a stronger packing structure for rising temperatures and equimolar compositions of solvent (ketone) and solute (edible oil).

As indicated above, the variation with mole fraction of the derived properties is almost symmetrical in these mixtures. This trend may be explained in terms of the following facts, i) the wide difference in terms of size and shape between solute (edible oil) and solvent (aliphatic ketone), ii) the loss of molecular association among likemolecules (dispersive interaction), iii) specific interactions among dislike-molecules and open structure with empty spaces.The negative values of excess molar volumes at almost any cases (and then, the strong positive change of refractive index on mixing) indicate that dislike intermolecular interactions is the dominant effect over the polarizable ketone structure and the dispersive interaction of triacylgycerides.

(a)

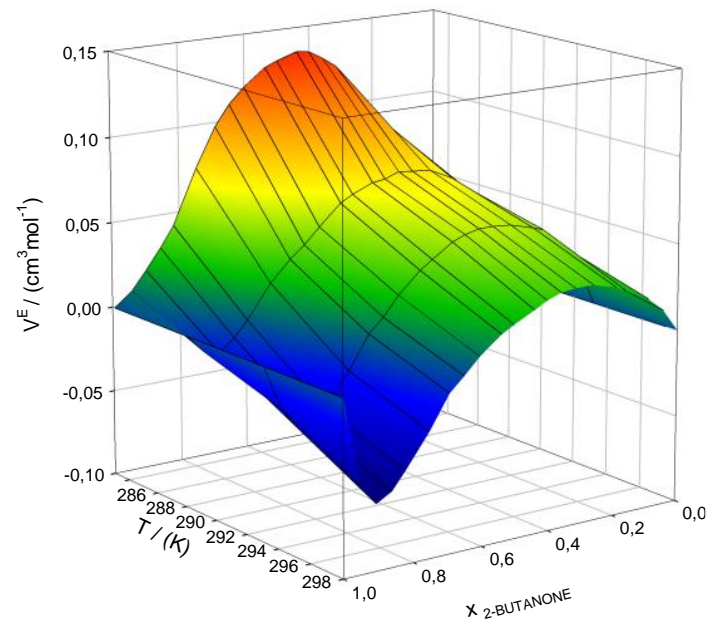

(b) 
(b)

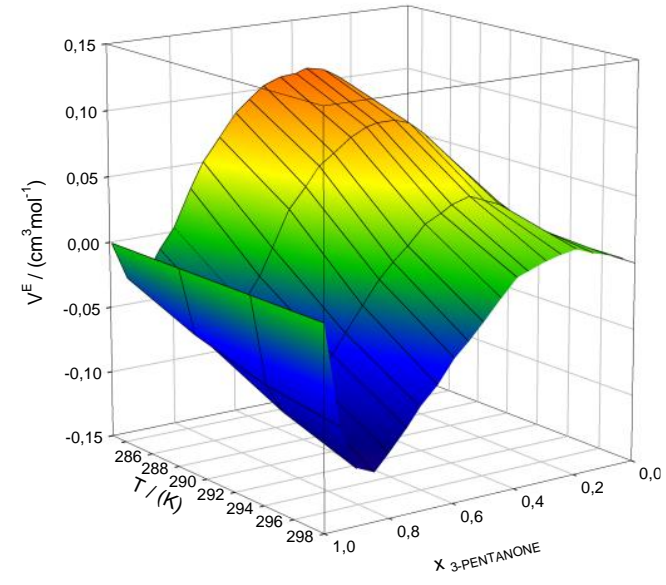

(c)

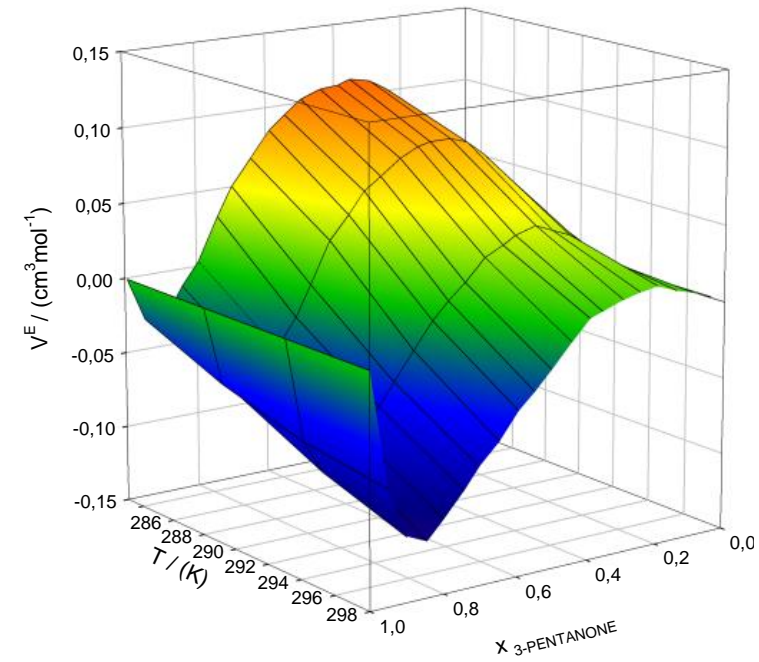

Fig. 1 Excess molar volumes $\left(\mathrm{cm}^{3} \mathrm{~mol}^{-1}\right)$ as a function of molar fraction for the following binary mixtures

(a) 2-butanone+olive oil, (b) 3-pentanone+olive oil,

(c) 4-methyl-2-pentanone+olive oil

(a)

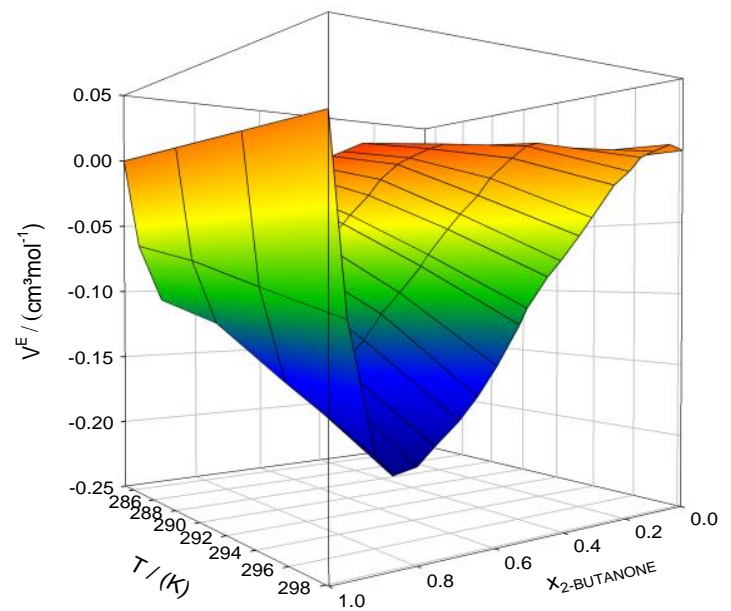

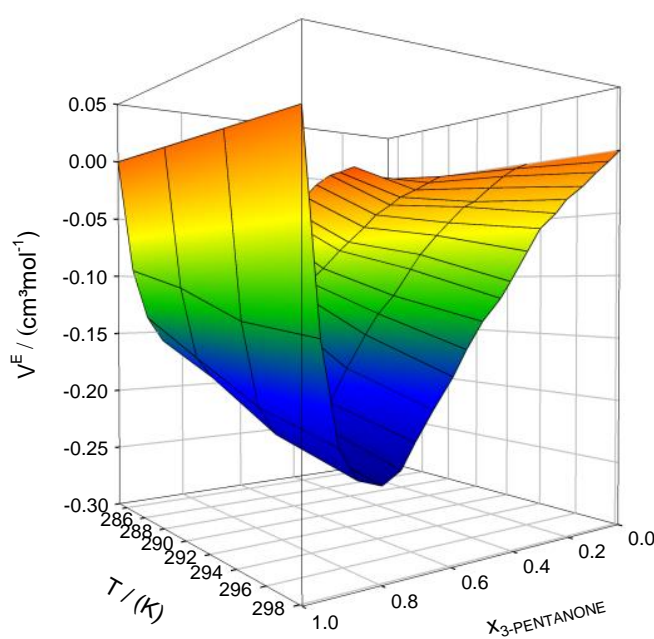

(c)

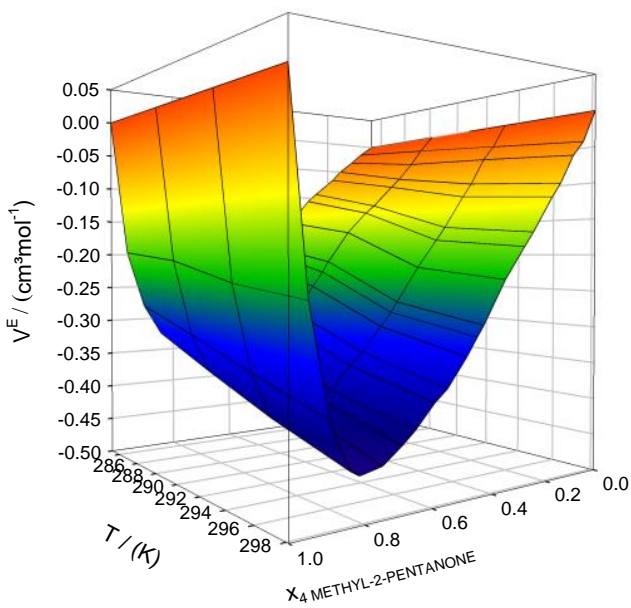

Fig. 2 Excess molar volumes $\left(\mathrm{cm}^{3} \mathrm{~mol}^{-1}\right)$ as a function of molar fraction for the following binary mixtures (a) 2-butanone+soybean oil, (b) 3pentanone+soybean oil, (c) 4-methyl-2pentanone+soybean oil

(a)

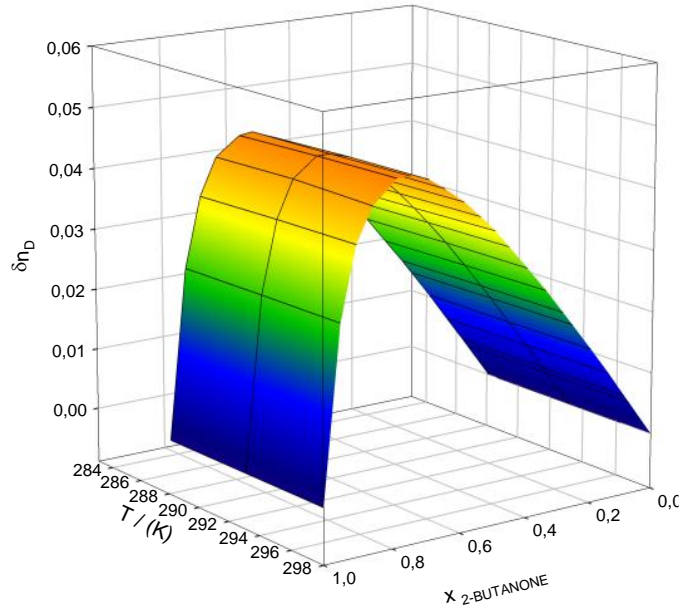

(b) 


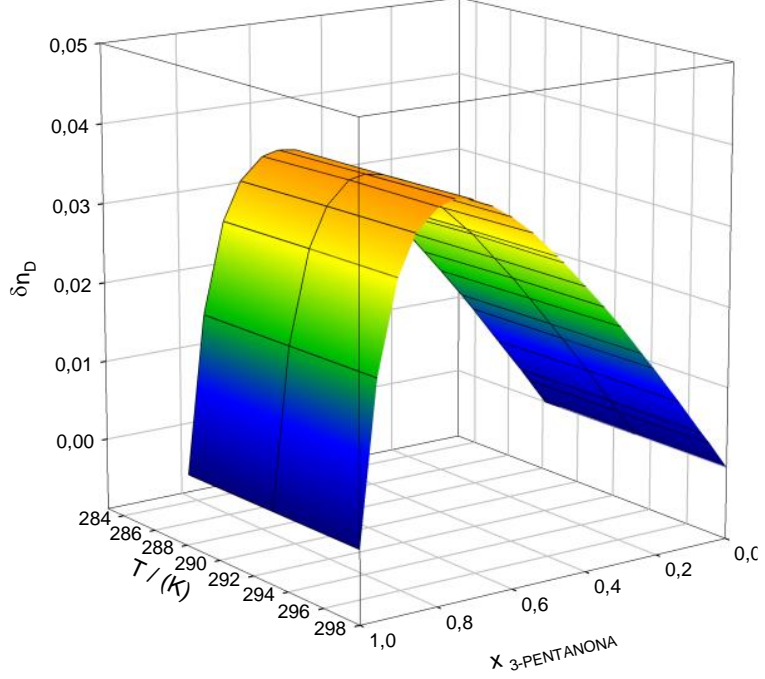

(c)

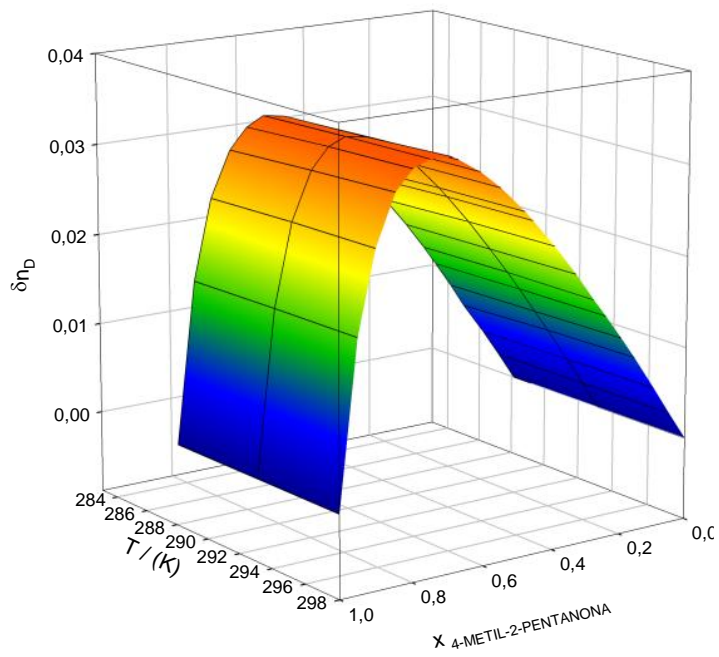

Fig. 3 Change do refractive index on mixing as a function of molar fraction for the following binary mixtures (a) 2-butanone+olive oil, (b) 3pentanone+olive oil, (c) 4-methyl-2-pentanone+olive oil

(a)

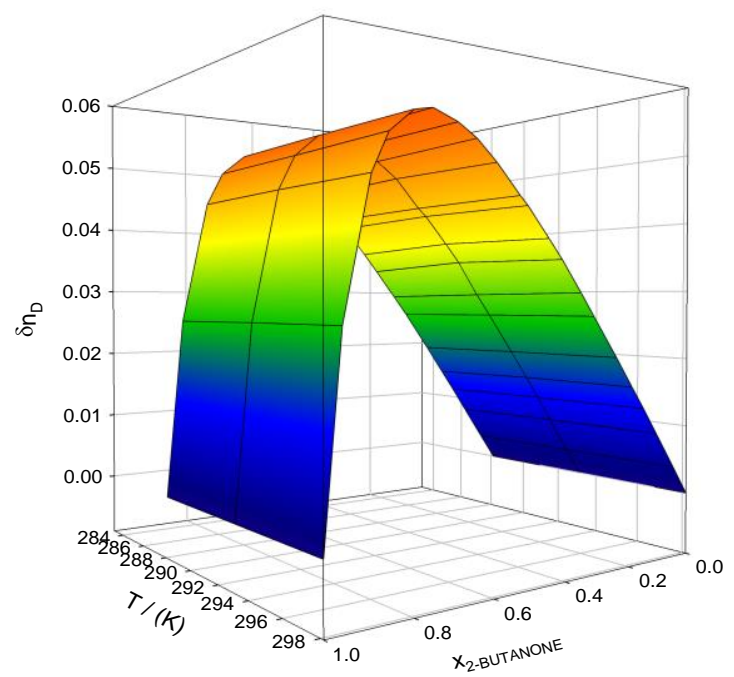

(b)

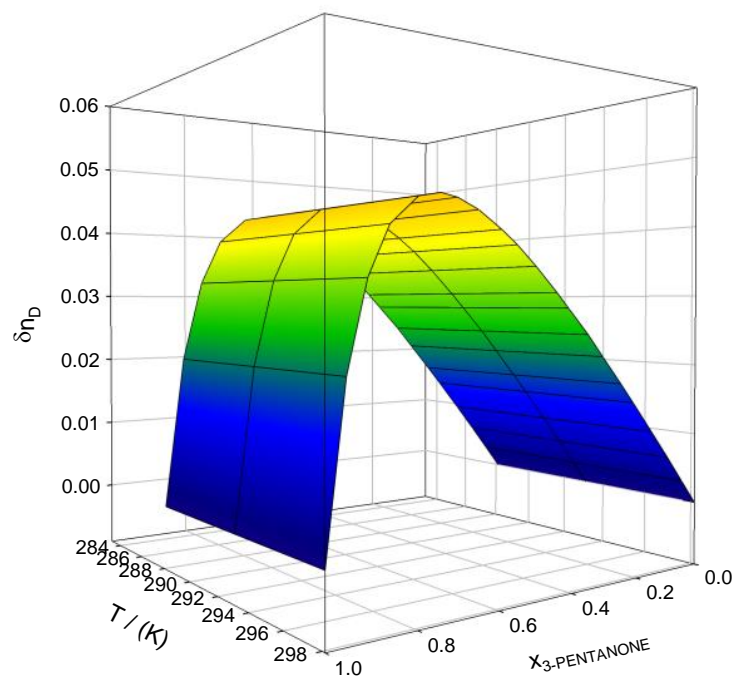

(c)

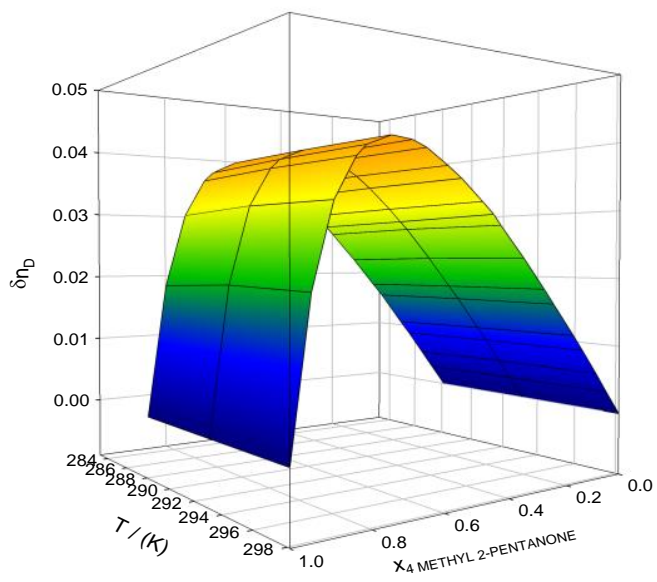

Fig. 4 Change do refractive index on mixing as a function of molar fraction for the following binary mixtures (a) 2-butanone+soybean oil, (b) 3pentanone+soybean oil, (c) 4-methyl-2pentanone+soybean oil

A relative high composition of unsaturated acids into these edible oils, which show cis-configuration at the double bonds, means that the triacylglycerides have relatively not compact structures, so that intermolecular forces between unsaturated triglyceride molecules are weaker than those in the corresponding saturated triacylglycerides.

If the equimolar values of the excess molar volumes are compared for both edible oils, the studied systems fall in a sequence as: 2-butanone < 3-pentanone < 4-methyl2-pentanone, being this sequence in agreement with the variation in molar mass of ketone and molar polarizability. This tendency is expected due to heavier aliphatic ketones, with higher molar polarizability character, show more intense interaction and higher non ideal mixing trend. 
Table 3 Fitting parameters and root mean square deviations for excess volumes for ketone + edible oil mixtures at different temperatures

\begin{tabular}{|c|c|c|c|c|}
\hline \multirow[b]{2}{*}{ Parameters } & \multicolumn{4}{|c|}{ 2-butanone+olive oil } \\
\hline & $\begin{array}{c}\mathrm{T}=298.15 \\
\mathrm{~K}\end{array}$ & $\begin{array}{c}\mathrm{T}=293.15 \\
\mathrm{~K}\end{array}$ & $\begin{array}{c}\mathrm{T}=288.15 \\
\mathrm{~K}\end{array}$ & $\mathrm{~T}=283.15 \mathrm{~K}$ \\
\hline$a_{1}$ & 0.1333 & 0.18143 & 0.26528 & 0.53321 \\
\hline $\mathrm{a}_{2}$ & -0.3912 & 0.24544 & 0.18597 & 0.12135 \\
\hline$a_{3}$ & -0.6671 & -0.27072 & -0.08301 & -0.02724 \\
\hline $\mathrm{a}_{4}$ & 0.5241 & 0.43646 & 0.35657 & 0.12379 \\
\hline$a_{5}$ & -1.1947 & - & - & -0.85731 \\
\hline$a_{6}$ & 0.8665 & - & - & 0.26811 \\
\hline \multirow[t]{2}{*}{$\sigma / \mathrm{cm}^{3} \cdot \mathrm{mol}^{-1}$} & $6.54 \cdot 10^{-4}$ & $1.17 \cdot 10^{-3}$ & $1.68 \cdot 10^{-3}$ & $1.11 \cdot 10^{-3}$ \\
\hline & \multicolumn{4}{|c|}{ 3-pentanone+olive oil } \\
\hline \multirow[t]{2}{*}{ Parameters } & $\mathrm{T}=298.15$ & $\mathrm{~T}=293.15$ & \multirow[t]{2}{*}{$\mathrm{T}=288.15 \mathrm{~K}$} & $\mathrm{~T}=283.15$ \\
\hline & K & $\mathrm{K}$ & & $\mathrm{K}$ \\
\hline $\mathrm{a}_{1}$ & -0.08395 & 0.06590 & 0.27484 & 0.41380 \\
\hline $\mathrm{a}_{2}$ & 0.49556 & 0.47123 & 0.41200 & 0.29912 \\
\hline $\mathrm{a}_{3}$ & -0.26421 & -0.21746 & -0.28052 & -0.21708 \\
\hline$a_{4}$ & 0.16236 & -0.03704 & 0.24332 & 0.11567 \\
\hline$a_{5}$ & -0.72441 & -0.82601 & -0.48263 & -0.24200 \\
\hline$a_{6}$ & 0.56138 & 0.65882 & 0.42245 & 0.67043 \\
\hline \multirow[t]{2}{*}{$\sigma / \mathrm{cm}^{3} \cdot \mathrm{mol}^{-1}$} & $1.30 \cdot 10^{-3}$ & $1.49 \cdot 10^{-3}$ & $2.15 \cdot 10^{-3}$ & $2.44 \cdot 10^{-3}$ \\
\hline & \multicolumn{4}{|c|}{ 4-methyl-2-pentanone+olive oil } \\
\hline Parameters & $\begin{array}{c}\mathrm{T}=298.15 \\
\mathrm{~K}\end{array}$ & $\begin{array}{c}\mathrm{T}=293.15 \\
\mathrm{~K}\end{array}$ & $\begin{array}{c}\mathrm{T}=288.15 \\
\mathrm{~K}\end{array}$ & $\mathrm{~T}=283.15 \mathrm{~K}$ \\
\hline$a_{1}$ & -0.86547 & -0.67924 & -0.51153 & -0.34624 \\
\hline $\mathrm{a}_{2}$ & 0.95664 & 1.04260 & 0.80089 & 0.59471 \\
\hline $\mathrm{a}_{3}$ & -0.66943 & -0.91704 & -0.82612 & -0.66641 \\
\hline $\mathrm{a}_{4}$ & 0.52747 & 0.07079 & 0.40294 & 1.00785 \\
\hline$a_{5}$ & -2.33729 & -0.64271 & -0.64146 & -0.80174 \\
\hline a6 & 0.70546 & 1.15659 & 0.95155 & - \\
\hline a7 & 1.56653 & - & - & - \\
\hline$\sigma / \mathrm{cm}^{3} \cdot \mathrm{mol}^{-1}$ & $3.43 \cdot 10^{-3}$ & $2.00 \cdot 10^{-3}$ & $2.43 \cdot 10^{-3}$ & $2.23 \cdot 10^{-3}$ \\
\hline
\end{tabular}

2-butanone+soybean oil

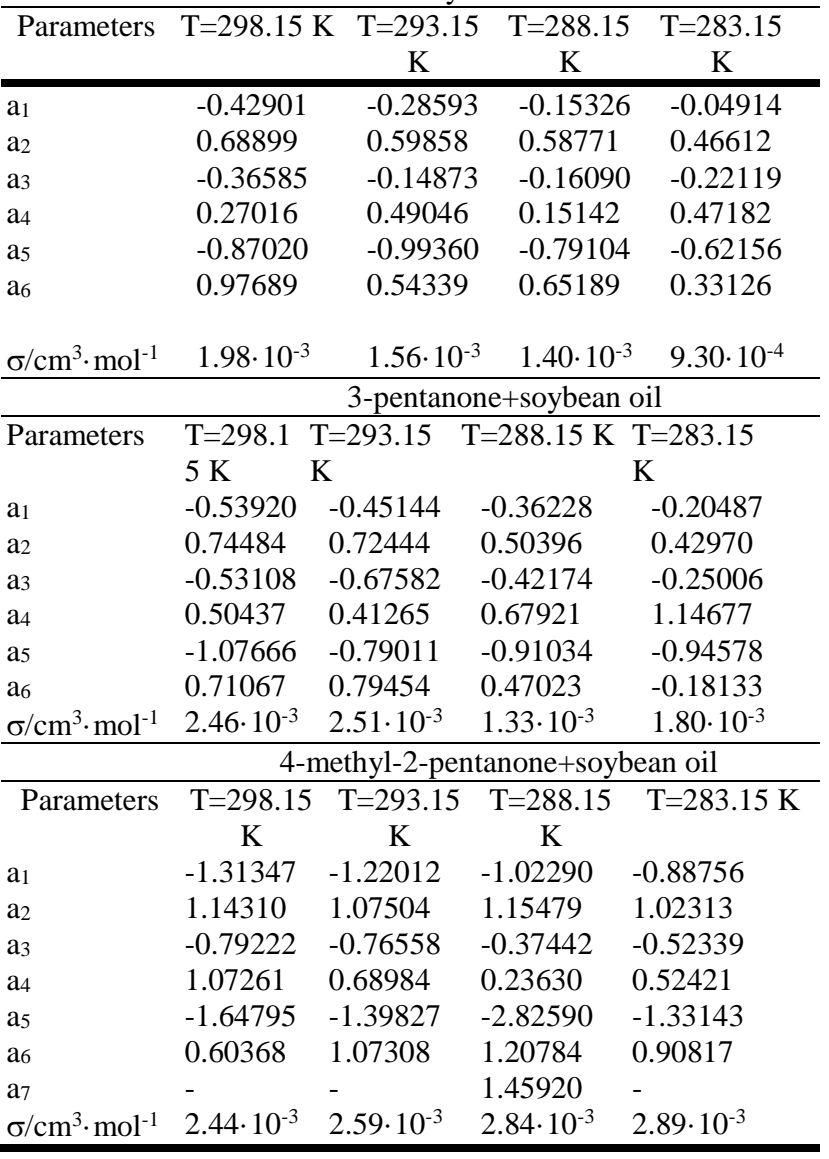

Table 4 Fitting parameters and root mean square deviations for change at different temperatures of refractive indices on mixing for ketone + edible oil mixtures

\begin{tabular}{|c|c|c|c|}
\hline \multirow{2}{*}{ Parameters } & \multicolumn{3}{|c|}{ 2-butanone+olive oil } \\
\hline & $\mathrm{T}=298.15 \mathrm{~K}$ & $\mathrm{~T}=293.15 \mathrm{~K}$ & $\mathrm{~T}=288.15 \mathrm{~K}$ \\
\hline $\mathrm{a}_{1}$ & 0.15065 & 0.14962 & 0.14831 \\
\hline$a_{2}$ & -0.13007 & -0.12838 & -0.12819 \\
\hline$a_{3}$ & 0.11819 & 0.11895 & 0.11866 \\
\hline $\mathrm{a}_{4}$ & -0.03201 & -0.04067 & -0.03566 \\
\hline$a_{5}$ & -0.02455 & -0.0231 & -0.02455 \\
\hline$a_{6}$ & -0.17886 & -0.16985 & -0.17319 \\
\hline$a_{7}$ & 0.20220 & 0.19935 & 0.19797 \\
\hline \multirow[t]{2}{*}{$\sigma$} & $2.03 \cdot 10^{-4}$ & $1.40 \cdot 10^{-4}$ & $1.58 \cdot 10^{-4}$ \\
\hline & \multicolumn{2}{|c|}{ 3-pentanone+olive oil } & \\
\hline Parameters & $\mathrm{T}=298.15 \mathrm{~K}$ & $\mathrm{~T}=293.15 \mathrm{~K}$ & $\mathrm{~T}=288.15 \mathrm{~K}$ \\
\hline $\mathrm{a}_{1}$ & 0.12371 & 0.12328 & 0.12192 \\
\hline$a_{2}$ & -0.10231 & -0.10144 & -0.10105 \\
\hline a3 & 0.0900 & 0.08425 & 0.08834 \\
\hline $\mathrm{a}_{4}$ & -0.03412 & -0.03527 & -0.03289 \\
\hline$a_{5}$ & -0.0056 & 0.01375 & -0.00499 \\
\hline $\mathrm{a} 6$ & -0.11284 & -0.11156 & -0.11354 \\
\hline a7 & 0.12149 & 0.10397 & 0.12176 \\
\hline & $8.88 \cdot 10^{-5}$ & $1.02 \cdot 10^{-4}$ & $8.38 \cdot 10^{-5}$ \\
\hline$\sigma$ & \multicolumn{3}{|c|}{ 4-methyl-2-pentanone+olive oil } \\
\hline Parameters & $\mathrm{T}=298.15 \mathrm{~K}$ & $\mathrm{~T}=293.15$ & $\begin{array}{ll}\mathrm{K} & \mathrm{T}=288.15 \mathrm{~K}\end{array}$ \\
\hline$a_{1}$ & 0.11414 & 0.11328 & 0.11152 \\
\hline $\mathrm{a}_{2}$ & -0.09072 & -0.08944 & -0.08866 \\
\hline $\mathrm{a} 3$ & 0.07149 & 0.07185 & 0.08031 \\
\hline $\mathrm{a}_{4}$ & -0.03165 & -0.03251 & -0.03297 \\
\hline$a_{5}$ & 0.02400 & 0.01331 & -0.02714 \\
\hline $\mathrm{a} 6$ & -0.0801 & -0.08045 & -0.07812 \\
\hline a7 & 0.06051 & 0.07327 & 0.11087 \\
\hline \multirow[t]{2}{*}{$\sigma$} & $9.51 \cdot 10^{-5}$ & $6.45 \cdot 10^{-5}$ & $7.22 \cdot 10^{-5}$ \\
\hline & \multicolumn{3}{|c|}{ 2-butanone+soybean oil } \\
\hline Parameters & $\begin{array}{c}\mathrm{T}=298.15 \\
\mathrm{~K}\end{array}$ & $\mathrm{~T}=293.15 \mathrm{~K}$ & $\mathrm{~T}=288.15 \mathrm{~K}$ \\
\hline$a_{1}$ & 0.16032 & 0.1606 & 0.15786 \\
\hline $\mathrm{a}_{2}$ & -0.13874 & -0.13631 & -0.13757 \\
\hline $\mathrm{a}_{3}$ & 0.12906 & 0.11344 & 0.12772 \\
\hline $\mathrm{a}_{4}$ & -0.03433 & -0.03669 & -0.02718 \\
\hline a5 & -0.02909 & 0.01267 & -0.03077 \\
\hline$a_{6}$ & -0.19585 & -0.19652 & -0.20605 \\
\hline$a_{7}$ & 0.21999 & 0.18684 & 0.21852 \\
\hline \multirow[t]{2}{*}{$\sigma$} & $2.08 \cdot 10^{-4}$ & $2.42 \cdot 10^{-4}$ & $1.65 \cdot 10^{-4}$ \\
\hline & \multicolumn{3}{|c|}{ 3-pentanone+soybean oil } \\
\hline Parameters & $\mathrm{T}=298.15 \mathrm{~K}$ & $\mathrm{~T}=293.15 \mathrm{~K}$ & $\mathrm{~T}=288.15 \mathrm{~K}$ \\
\hline $\mathrm{a}_{1}$ & 0.13352 & 0.13234 & 0.13139 \\
\hline $\mathrm{a}_{2}$ & -0.11001 & -0.10832 & -0.10978 \\
\hline $\mathrm{a}_{3}$ & 0.09373 & 0.09289 & 0.09209 \\
\hline $\mathrm{a}_{4}$ & -0.03854 & -0.04317 & -0.02805 \\
\hline a5 & 0.00794 & 0.01347 & 0.00903 \\
\hline a6 & -0.1198 & -0.11666 & -0.13392 \\
\hline a7 & 0.11862 & 0.1137 & 0.11788 \\
\hline \multirow[t]{2}{*}{$\sigma$} & $9.34 \cdot 10^{-5}$ & $1.25 \cdot 10^{-4}$ & $1.03 \cdot 10^{-4}$ \\
\hline & \multicolumn{3}{|c|}{ 4-methyl-2-pentanone+soybean oil } \\
\hline $\begin{array}{l}\text { Parameter } \\
\mathrm{s}\end{array}$ & $\mathrm{T}=298.15 \mathrm{~K}$ & $\mathrm{~T}=293.15 \mathrm{~K}$ & $\mathrm{~T}=288.15 \mathrm{~K}$ \\
\hline $\mathrm{a}_{1}$ & 0.12375 & 0.12299 & 0.12155 \\
\hline $\mathrm{a}_{2}$ & -0.09628 & -0.09816 & -0.09651 \\
\hline$a_{3}$ & 0.07199 & 0.07901 & 0.07946 \\
\hline $\mathrm{a}_{4}$ & -0.04207 & -0.0302 & -0.03803 \\
\hline a5 & 0.03930 & 0.01221 & 0.01597 \\
\hline a6 & -0.08029 & -0.09700 & -0.08163 \\
\hline a7 & 0.05859 & 0.08904 & 0.07139 \\
\hline$\sigma$ & $9.61 \cdot 10^{-5}$ & $8.42 \cdot 10^{-5}$ & $9.43 \cdot 10^{-5}$ \\
\hline
\end{tabular}


Partial molar quantities are important in the study of the dependence of an extensive property on the phase composition at constant pressure and temperature, since show its trend with molar fraction variation. They should be applied to any extensive property of a singlephase system such as volume, Gibbs energy or any other. If we let $\mathrm{E}$ represent any extensive property of a single phase which is a function of pressure, temperature and mole numbers of the components, the differential of $E$ should be expressed as:

$$
\delta \mathrm{E}=\left(\frac{\partial \mathrm{E}}{\partial \mathrm{T}}\right)_{\mathrm{P}, \mathrm{n}} \mathrm{dT}+\left(\frac{\partial \mathrm{E}}{\partial \mathrm{P}}\right)_{\mathrm{T}, \mathrm{n}} \mathrm{dP}+\sum_{\mathrm{i}=1}^{\mathrm{N}}\left(\frac{\partial \mathrm{E}}{\partial \mathrm{n}_{\mathrm{i}}}\right)_{\mathrm{T}, \mathrm{P}, \mathrm{n}} \mathrm{dn}_{\mathrm{i}}
$$

where the quantity $\left(\partial \mathrm{E} / \partial \mathrm{n}_{\mathrm{i}}\right)_{\mathrm{T}, \mathrm{P}, \mathrm{n}}$ is defined as the partial molar quantity of the $\mathrm{i}^{\text {th }}$ component in the phase, the value $\mathrm{N}$ refers to all the other components present, showing the finite change in the property on the addition of $1 \mathrm{~mol}$ of the component $\mathrm{i}$ in an infinite quantity of solution at constant temperature and pressure. In what is referred to an excess property, the partial excess molar volume of a component in a binary mixture can be determined from excess molar volume data by means of the following expression:

$$
\bar{V}_{i}^{E}=V^{E}+\left(1-x_{i}\right)\left(\frac{d V^{E}}{d x_{i}}\right)
$$

where the differential term is calculated taking into account we have applied the Redlich-Kister expression to correlate the excess values, thus parameters enclosed in Table 3 for eq. 7 are applied. The partial excess molar volumes, once the differentiation is performed and some algebra carried out, should be written as:

$\overline{\mathrm{V}}_{1}^{\mathrm{E}}=\left(1-\mathrm{x}_{1}\right)^{2}\left[\sum_{\mathrm{p}=0}^{\mathrm{m}} \mathrm{a}_{\mathrm{p}}\left(2 \mathrm{x}_{1}-1\right)^{\mathrm{p}}+\mathrm{x}_{1} \sum_{\mathrm{p}=1}^{\mathrm{m}} 2 \mathrm{pa}_{\mathrm{p}}\left(2 \mathrm{x}_{1}-1\right)^{\mathrm{p}-1}\right]$

$\overline{\mathrm{V}}_{2}^{\mathrm{E}}=\left(1-\mathrm{x}_{2}\right)^{2}\left[\sum_{\mathrm{p}=0}^{\mathrm{m}} \mathrm{a}_{\mathrm{p}}\left(1 \cdot \overline{\mathrm{V}}_{2}^{\mathrm{E}}-\mathrm{x}_{2} \sum_{\mathrm{p}=1}^{\mathrm{m}}(-2) \mathrm{pa}_{\mathrm{p}}\left(1-2 \mathrm{x}_{2}\right)^{\mathrm{p}-1}\right]\right.$

and the symbols keep the meaning explained above. From eqs. 8 and 9, the corresponding limiting partial excess molar volumes should be determined by considering $\mathrm{x}_{\mathrm{i}}$ null in every expression, such limiting values being depending only on these correlation parameters. Figure 5a (olive oil mixtures) and 5b (soybean oil mixtures) show the trends of partial excess molar volumes with the molar fraction for the binary mixtures at $298.15 \mathrm{~K}$. As observed, the strongest variation in terms of partial excess molar magnitude are those of 4-methyl-2-pentanone, due to low variations of ketone composition result in stronger negative values of excess molar volume at this temperature. Enclosed into Figure $5 \mathrm{a}$ and $5 \mathrm{~b}$, it should be observed a magnified view of the inflection point, where curves corresponding to 2-butanone for both edible oils show a clear opposite evolution (slight positive for olive oil and slight negative for soybean oil).

Table 5. Partial excess molar volumes at infinite dilution of the binary mixtures at $298.15 \mathrm{~K}$

$\begin{array}{cc}\overline{\mathrm{V}}_{1}^{\mathrm{E}, \infty} & \overline{\mathrm{V}}_{2}^{\mathrm{E}, \infty} \\ /\left(\mathrm{cm}^{3} \mathrm{~mol}^{-1}\right) & /\left(\mathrm{cm}^{3} \mathrm{~mol}^{-1}\right)\end{array}$

\begin{tabular}{lll}
\hline 2-butanone (1) + olive oil (2) & -2.728 & -0.729 \\
3-pentanone (1) olive oil (2) & 5.255 & -1.364 \\
4-methyl-2-pentanone (1) + olive & -3.245 & -3.501 \\
oil (2) & & \\
2-butanone (1) + soybean oil (2) & 0.449 & -2.155 \\
3-pentanone (1) + soybean oil (2) & 1.074 & -2.694 \\
4-methyl-2-butanone (1) + soybean & -17.281 & -4.526 \\
oil (2) & & \\
\hline
\end{tabular}

(a)

$\overline{\mathbf{V}}_{1}^{\mathrm{E}}$
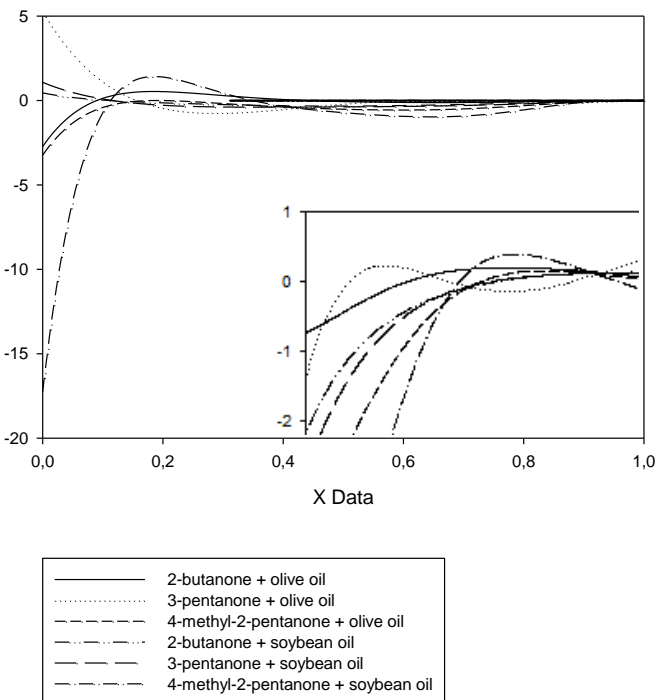

(b)
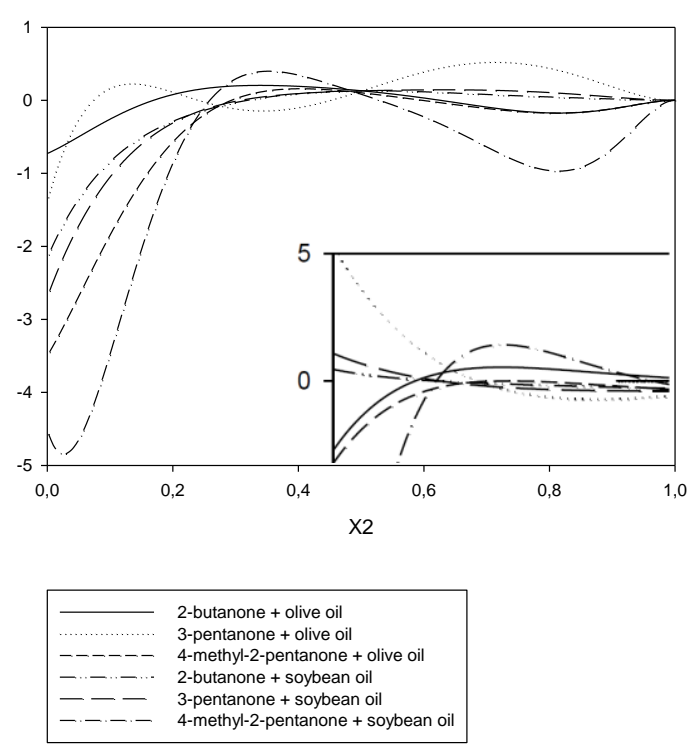

FIGURE 5 Partial excess molar volumes $\left(\mathrm{cm}^{3} \mathrm{~mol}^{-1}\right)$ of the binary systems, (a) and (b) $\bar{V}_{2}^{E}$ at $298.15 \mathrm{~K}$. 
In Table 5, the values of limiting partial excess molar volumes at $298.15 \mathrm{~K}$ for the binary mixtures are enclosed, which depicts the trend at infinite dilution condition.

\section{Physical Properties Estimation}

The prediction of different thermodynamic properties of binary or multicomponent mixtures has been the subject of a wide study in recent years, applying different empirical or semiempirical models. In this paper, the measured experimental properties were compared with those estimated applying several relations, corresponding states procedures and equations of state for density and different semiempirical rules for refractive index on mixing. Primarily, using the Gani-Constantinou method [44, 45], the critical properties not previously published for the fatty acids were estimated. For the other components, the critical values were collected from open literature (Table 6) [46, 47].

Table 6 Estimated critical values using ConstantinouGani[44-45] method.

\begin{tabular}{lcccc}
\hline & $\mathrm{P}_{\mathrm{c}}(\mathrm{bar})$ & $\mathrm{T}_{\mathrm{c}}(\mathrm{K})$ & $\mathrm{Z}_{\mathrm{c}}$ & $\omega$ \\
\hline 2-Butanone & $41.5^{\mathrm{a}}$ & $535.5^{\mathrm{a}}$ & $0.249^{\mathrm{a}}$ & $0.32337^{\mathrm{a}}$ \\
3-Pentanone & $37.4^{\mathrm{a}}$ & $560.95^{\mathrm{a}}$ & $0.269^{\mathrm{a}}$ & $0.34485^{\mathrm{a}}$ \\
4-Methyl-2-pentanone & $32.7^{\mathrm{a}}$ & $574.6^{\mathrm{a}}$ & $0.253^{\mathrm{a}}$ & $0.35567^{\mathrm{a}}$ \\
Palmitic Acid & 15.1 & 785.00 & 0.212 & 0.98271 \\
Palmitoleic Acid & $15.4^{\mathrm{b}}$ & $887.89^{\mathrm{b}}$ & 0.196 & 1.08230 \\
Stearic Acid & 13.6 & 804.00 & 0.208 & 1.03600 \\
Oleic Acid & 13.9 & 781.00 & 0.214 & 1.18200 \\
Linoleic Acid & 14.1 & 775.00 & 0.217 & 1.18000 \\
Linolenic Acid & 14.4 & 780.00 & 0.238 & 1.18700 \\
Behenic Acid & $9.9^{\mathrm{b}}$ & $1039.78^{\mathrm{b}}$ & 0.148 & 1.30990 \\
\hline
\end{tabular}

[ [46]; ${ }^{b}[47]$

Several models have been evaluated in this study; the selection of models was based on ease of use, accuracy, and range of application.

In this case, a simplification for the NasrifarMoshfeghian liquid density correlation (NM correlation) was applied, replacing the Mathias and Copeman temperature-dependent term with the original Soave-Redlich-Kwong equation of state (SRK EOS) temperature-dependent term. This replacement has overcome the limitations in use for the original model which were due to the Mathias and Copeman vapor pressure dependent parameters [32, 33]. The NasrifarMoshfeghian model (NM) requires three parameters for each compound, that are not readily available for all compounds. In the absence of these three parameters, the NM correlation fails to predict the density of pure compounds and their mixtures. The modification of this model, Mchaweh-Nasrifar-Moshfeghian model (MNM), overcomes this barrier by replacing the PSRK (Predictive Soave-Redlich-Kwong) parameter $\alpha$ with the original SRK term $\left(\alpha_{\mathrm{SRK}}\right)$. The parameter $\alpha_{\mathrm{SRK}}$ is defined in terms of reduced temperature $\left(T_{R}\right)$ :

$$
\begin{aligned}
& \rho / \rho_{\mathrm{C}}=1+(1.69+0.984 \cdot \omega) /\left(1-\mathrm{T}_{\mathrm{R}}\right)^{1 / 3} \\
& +0.85 \cdot\left(1-\mathrm{T}_{\mathrm{R}}\right) \\
& \alpha_{\mathrm{SRK}}=\left[1+\dot{\mathrm{m}} \cdot\left(1-\sqrt{\mathrm{T}_{\mathrm{R}}}\right)\right]^{2}
\end{aligned}
$$

where $\mathrm{m}$ is given by the following relation as a function of acentric factor $(\omega)$ :

$$
\dot{\mathrm{m}}=0.480+1.574 \cdot \omega-0.176 \cdot \omega^{2}
$$

The revised model, after replacement, has the following general formula:

$$
\rho=\rho_{\mathrm{C}} \cdot \rho_{0} \cdot\left\lfloor 1+\delta_{\mathrm{SRK}} \cdot\left(\alpha_{\mathrm{SRK}}-1\right)^{1 / 3}\right\rfloor
$$

where $\rho_{\mathrm{C}}$ is the critical density and the parameter $\delta_{\mathrm{SRK}}$ is a new characteristic parameter for each compound.

$$
\delta_{\text {SRK }}=0.1596 \cdot \omega-0.0319
$$

The parameter $\rho_{0}$ is the reference density and is calculated by the following equation:

$$
\begin{aligned}
& \rho_{0}=1+1.1688 \cdot\left(1-\frac{\mathrm{T}_{\mathrm{R}}}{\alpha_{\mathrm{SRK}}}\right)^{1 / 3}+1.8177 \cdot\left(1-\frac{\mathrm{T}_{\mathrm{R}}}{\alpha_{\mathrm{SRK}}}\right)^{2 / 3} \\
& -2.6581 \cdot\left(1-\frac{\mathrm{T}_{\mathrm{R}}}{\alpha_{\mathrm{SRK}}}\right)^{3 / 3}+2.1613 \cdot\left(1-\frac{\mathrm{T}_{\mathrm{R}}}{\alpha_{\mathrm{SRK}}}\right)^{4 / 3}
\end{aligned}
$$

This model gathers slight underestimated values for the all mixtures, showing the highest deviations at high solvent compositions for the mixtures of 3-pentanone. In both edible oil mixtures, the temperature is a secondary factor and slightly affects the final capability of prediction of the MNM model.

The Heller equation [34] was modified to estimate the volumetric trend of these mixtures as a function or temperature and composition, as follows:

$$
1 / \rho=\sum_{i=1}^{N}\left(\frac{w_{i}}{\sum_{i=0}^{N} \sum_{j=0}^{M} D_{i j} \cdot T^{j}}\right)
$$

where $\mathrm{i}$ stands for the corresponding compounds into the binary mixture and $\mathrm{w}_{\mathrm{i}}$ stands for the mass fraction. Attending to the measured data, the estimation of density was made as function of temperature, so, data at different temperatures for edible oils and solvents are necessary. Both the experimental and predicted (Halvorsen equation) density data of each pure oilwere applied by means a polynomial. One proposed correlation that holds promise for application to oils is the Rackett equation of state. The modification of this equation by Halvorsen et al. [35] has demonstrated to be accurate, only requiring critical magnitudes for the enclosed fatty acids. If these magnitudes are not known, they must be estimated. The method of Halvorsen is described as follows:

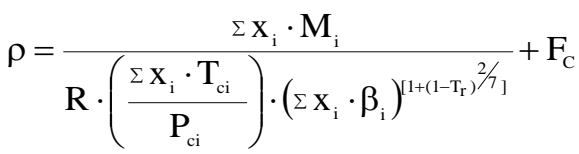

where $\rho$ is the oil density, $x_{i}$ is the mole fraction of fatty acids into that oil, $\mathrm{M}_{\mathrm{i}}$ is the molar mass of each fatty acid, $\mathrm{R}$ is the universal constant of gases, $\mathrm{P}_{\mathrm{ci}}$ is the critical pressure of each fatty acid and $T_{r}$ is the reduced temperature. The $\beta$ parameter is the compressibility 
factor for the original equation of Rackett $(\mathrm{Zc})$ or an acentric factor dependent parameter if we use the modified Rackett equation $\left(\mathrm{Z}_{\mathrm{RA}}\right)$ [37]. The mixing rule to compute the pseudocritical temperature, and then the reduced temperature of the oil is described as follows:

$$
\mathrm{T}_{\mathrm{r}}=\frac{\mathrm{T}}{\sum \mathrm{x}_{\mathrm{i}} \mathrm{T}_{\mathrm{ci}}}
$$

$\mathrm{Fc}$ is a correction factor proposed by Halvorsen which depends on the oil structure backbone. The correction factor equation for the studied is:

$$
\mathrm{F}_{\mathrm{c}}=0.0236+0.000082 \cdot\left(875-\mathrm{M}_{\text {oil }}\right)
$$

where $\mathbf{M}_{\text {oil }}$ is the molar mass of each studied oil, as gathered into Table 1. Table 7 shows the percent error for density predictions by Halvorsen's model (HM) versus experimental data at different temperatures.

Table7. \% Deviations $\left(\mathrm{g} / \mathrm{cm}^{3}\right)$ for Halvorsen method density prediction for the studied vegetable oils at 283.15, 288.15, 293.15 and $298.15 \mathrm{~K}$

\begin{tabular}{ccc}
\hline $\mathrm{T}(\mathrm{K})$ & Olive Oil & Soybean Oil \\
\hline 283.15 & 6.18 & 6.02 \\
288.15 & 6.20 & 6.03 \\
293.15 & 6.22 & 6.04 \\
298.15 & 6.22 & 5.92 \\
\hline
\end{tabular}

In Figures6, a comparison of the estimated densities is enclosed for the MNM model.Figures 7-8 show as an example a deviation between experimental and theoretical densityfor Olive and Soybean oils + 2Butanone at 298.15 K using a Modified Heller Equation applied from experimental (Figures 7A and 8A) and estimated (Figures 7B and 8B) density data of pure oils. The root mean square deviations between experimental and estimated data are shown in the Table 8.It could be observed as MNM slight overpredicts the density values, showing the betterresults, at any case, at extreme solvent compositions. Comparatively, MHE offers much better results in terms of deviation than MNM for these mixtures.

A percentage error around6\% is observed in the pure oil density estimation by Halvorsen equation, what justified the higher root mean square deviations for the MHE computed from estimated density pure oils data in relation with that computed from experimental density data.

Table 8 Root mean square deviations (Eq. 2) for predictive density values by amodified Heller (MHE) equation with respect to corresponding experimental data at $283.15-298.15 \mathrm{~K}$.

\begin{tabular}{cccc}
\hline Mixture & MNM & MHE* & MHE** \\
\hline 1 & $6.76703 \mathrm{E}-02$ & $2.01667 \mathrm{E}-02$ & $1.65580 \mathrm{E}-07$ \\
2 & $8.35128 \mathrm{E}-02$ & $1.96195 \mathrm{E}-02$ & $1.82308 \mathrm{E}-07$ \\
3 & $5.48868 \mathrm{E}-02$ & $1.85983 \mathrm{E}-02$ & $1.65750 \mathrm{E}-06$ \\
4 & $6.34720 \mathrm{E}-02$ & $1.92204 \mathrm{E}-02$ & $1.61568 \mathrm{E}-06$ \\
5 & $8.06748 \mathrm{E}-02$ & $1.84418 \mathrm{E}-02$ & $1.93519 \mathrm{E}-06$ \\
6 & $5.25400 \mathrm{E}-02$ & $1.70264 \mathrm{E}-02$ & $1.95904 \mathrm{E}-05$ \\
\hline
\end{tabular}

Mixture 1: 2-butanone + olive oil

Mixture 2: 3-pentanone + olive oil

Mixture 3: 4-methyl-2-pentanone + olive oil

Mixture 4: 2-butanone + soybean oil

Mixture 5: 3-pentanone + soybean oil

Mixture 6: 4-methyl-2-pentanone + soybean oil

*Calculated from experimental density data of pure components.

$* *$ Calculated from estimated density data of pure oils.
In what is referred to estimate the refractive indices on mixing, different semiempirical rules were applied, which are dependent on the pure values at the studied temperature. The experimental refractive indices on mixing have been compared with the estimated ones by means of the mixing rules proposed by Lorentz-Lorenz (eq. 24), Dale and Gladstone (eq. 25), Eykman (eq. 26), Arago-Biot (eq. 27) Newton (eq. 28), Oster (eq. 29), Eyring and John (eq. 30), Weiner (eq. 31) and Heller (eq. 32) [31]:

$$
\begin{aligned}
& \frac{\mathrm{n}_{\mathrm{D}}^{2}-1}{\mathrm{n}_{\mathrm{D}}^{2}+2}=\sum_{\mathrm{i}=1}^{\mathrm{N}}\left[\phi_{\mathrm{i}}\left(\frac{\mathrm{n}_{\mathrm{Di}}^{2}-1}{\mathrm{n}_{\mathrm{Di}}^{2}+2}\right)\right] \\
& \mathrm{n}_{\mathrm{D}}-1=\sum_{\mathrm{i}=1}^{\mathrm{N}}\left[\phi_{\mathrm{i}}\left(\mathrm{n}_{\mathrm{Di}}-1\right)\right] \\
& \frac{\mathrm{n}_{\mathrm{D}}^{2}-1}{\mathrm{n}_{\mathrm{D}}^{2}+0.4}=\sum_{\mathrm{i}=1}^{\mathrm{N}}\left[\phi_{\mathrm{i}}\left(\frac{\mathrm{n}_{\mathrm{Di}}^{2}-1}{\mathrm{n}_{\mathrm{Di}}^{2}+0.4}\right)\right] \\
& \mathrm{n}_{\mathrm{D}}=\sum_{\mathrm{i}=1}^{\mathrm{N}}\left(\phi_{\mathrm{i}} \mathrm{n}_{\mathrm{Di}}\right)=\sum_{\mathrm{i}=1}^{\mathrm{N}}\left[\phi_{\mathrm{i}}\left(\mathrm{n}_{\mathrm{Di}}^{2}-1\right)\right] \\
& \frac{\left(\mathrm{n}_{\mathrm{D}}^{2}-1\right)-\left(2 \mathrm{n}_{\mathrm{D}}^{2}+1\right)}{\mathrm{n}_{\mathrm{D}}^{2}}=\sum_{\mathrm{i}=1}^{\mathrm{N}}\left[\phi_{\mathrm{i}}\left(\frac{\left(\mathrm{n}_{\mathrm{Di}}^{2}-1\right)-\left(2 \mathrm{n}_{\mathrm{Di}}^{2}+1\right)}{\mathrm{n}_{\mathrm{Di}}^{2}}\right)\right]
\end{aligned}
$$

And for binary mixtures

$$
\begin{aligned}
\mathrm{n}_{\mathrm{D}}= & \mathrm{n}_{\mathrm{D} 1} \phi_{1}^{2}+2\left(\mathrm{n}_{\mathrm{D} 1} \mathrm{n}_{\mathrm{D} 2}\right)^{1 / 2} \phi_{1} \phi_{2}+\mathrm{n}_{\mathrm{D} 2} \phi_{2}^{2} \\
& \frac{\mathrm{n}_{\mathrm{D}}^{2}-\mathrm{n}_{\mathrm{D} 1}^{2}}{\mathrm{n}_{\mathrm{D}}^{2}+2 \mathrm{n}_{\mathrm{D} 1}^{2}}=\left[\phi_{2} \frac{\mathrm{n}_{\mathrm{D} 2}^{2}-\mathrm{n}_{\mathrm{D} 1}^{2}}{\mathrm{n}_{\mathrm{D} 2}^{2}+2 \mathrm{n}_{\mathrm{D} 1}^{2}}\right] \\
& \frac{\mathrm{n}_{\mathrm{D}}-\mathrm{n}_{\mathrm{D} 1}}{\mathrm{n}_{\mathrm{D} 1}}=\left[\frac{3}{2} \phi_{2} \frac{\left(\mathrm{n}_{\mathrm{D} 2} / \mathrm{n}_{\mathrm{D} 1}\right)^{2}-1}{\left(\mathrm{n}_{\mathrm{D} 2} / \mathrm{n}_{\mathrm{D} 1}\right)^{2}+2}\right]
\end{aligned}
$$

where

$$
\phi_{i}=\frac{\left[\frac{x_{i} M_{i}}{\rho_{i}}\right]}{\sum_{i=1}^{N}\left[\frac{x_{i} M_{i}}{\rho_{i}}\right]}
$$

As observed in Table 9, better results are obtained for olive oil mixtures but at any case, these semiempirical rules gather accurate results at any composition or temperature condition.In Figure 9, as example, a comparison of deviations is gathered for both edible oils using the Lorenz-Lorentz equation at $298.15 \mathrm{~K}$ 
Table 9. Root mean square deviations at $298.15 \mathrm{~K}$ of the experimental refractive indices from the estimation results for the Lorentz-Lorenz (LL), Dale-Gladstone (DG),Arago-Biot (AB),Eykman (Ey), Newton (Nw), Oster (Os), Wiener (Wi) and Heller $(\mathrm{He})$ equations

\begin{tabular}{lcccccccc}
\hline & LL & DG & AB & Ey & Nw & Os & Wi & He \\
\hline \multicolumn{7}{c}{ Olive Oil } \\
2-Butanone & 0.00045 & 0.00013 & 0.00013 & 0.00021 & 0.00034 & 0.0002 & 0.00676 & 0.00102 \\
3-Pentanone & 0.0004 & 0.00012 & 0.00012 & 0.00021 & 0.00017 & 0.00006 & 0.00472 & 0.00073 \\
4-m-2-Pentanone & 0.00067 & 0.0004 & 0.0004 & 0.00048 & 0.00015 & 0.00025 & 0.00397 & 0.00091 \\
\hline & & \multicolumn{7}{c}{ Soybean Oil } \\
\hline 2-Butanone & 0.00074 & 0.00032 & 0.00032 & 0.00044 & 0.00015 & 0.00012 & 0.00743 & 0.00132 \\
3-Pentanone & 0.00064 & 0.00031 & 0.00031 & 0.00041 & 0.00008 & 0.00014 & 0.00526 & 0.00101 \\
4-m-2-Pentanone & 0.00091 & 0.0006 & 0.0006 & 0.00069 & 0.0003 & 0.00042 & 0.00449 & 0.00119 \\
\hline
\end{tabular}

$\delta n_{D}$

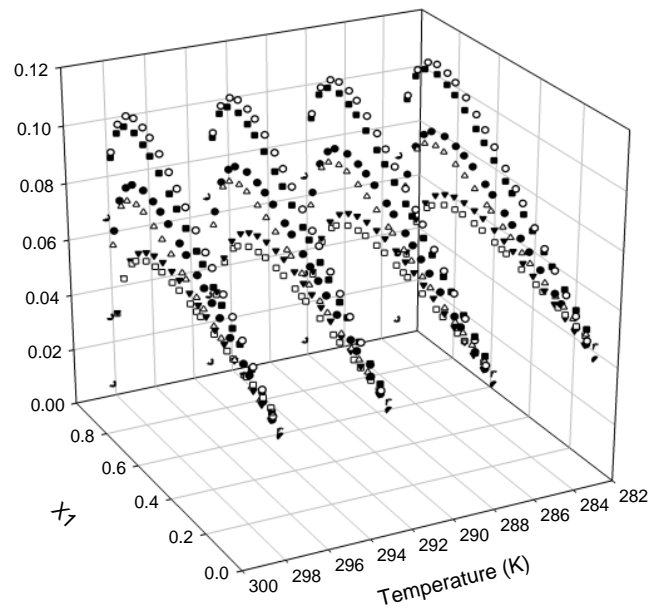

$$
\begin{array}{ll}
\text { - } & \text { 2-butanone + olive oil } \\
\circ & \text { 3-pentanone + olive oil } \\
\text { प } & \text { 4-methyl-2-pentanone + olive oil } \\
\Delta & \text { 2-butanone + soybean oil } \\
\text { - } & \text { 3-pentanone + soybean oil } \\
\text { व } & \text { 4-methyl-2-pentanone + soybean oil }
\end{array}
$$

FIGURE 6 Deviation between experimental and theoretical density (MNM model) for temperatures 298.15 K, 293.15 K, 288.15 K and 283.15 K for all binary mixtures

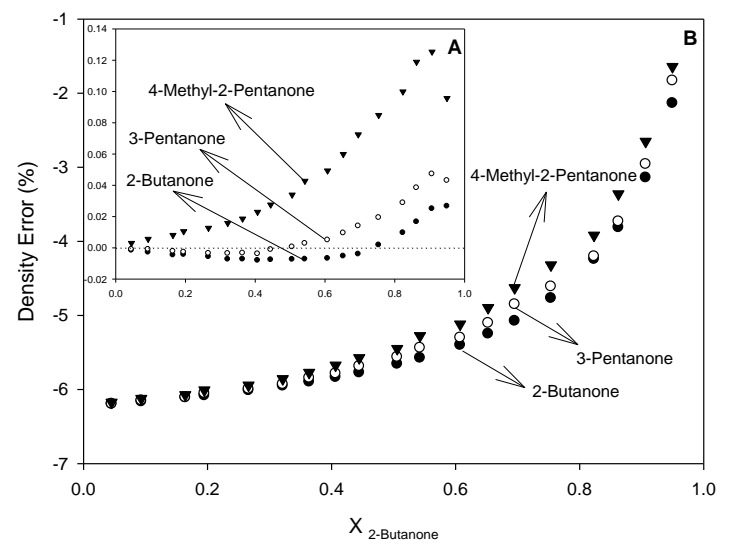

FIGURE 7 Deviation between experimental and theoretical densityfor Olive oil +2 -Butanone at 298.15 K using a Modified Heller Equationapplied from experimental (graph A) and estimated (graph B) density data of pure oils.

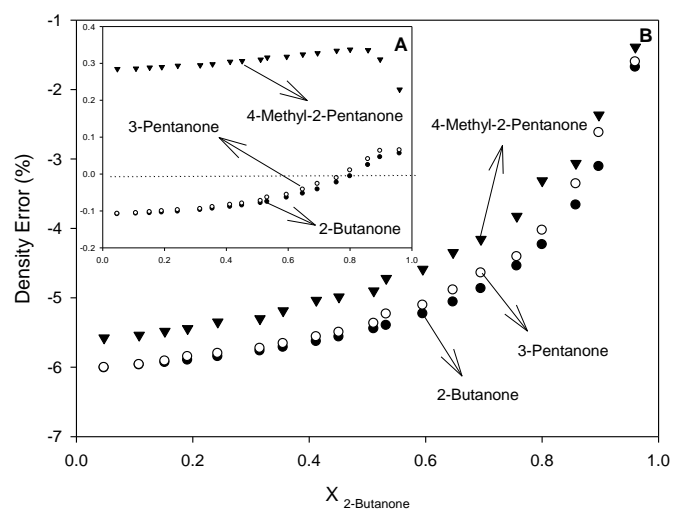

FIGURE 8Deviation between experimental and theoretical densityfor Soybean oil +2 -Butanone at 298.15 K using a Modified Heller Equation applied from experimental (graph A) and estimated (graph B) density data of pure oils.

$\delta n_{D}$

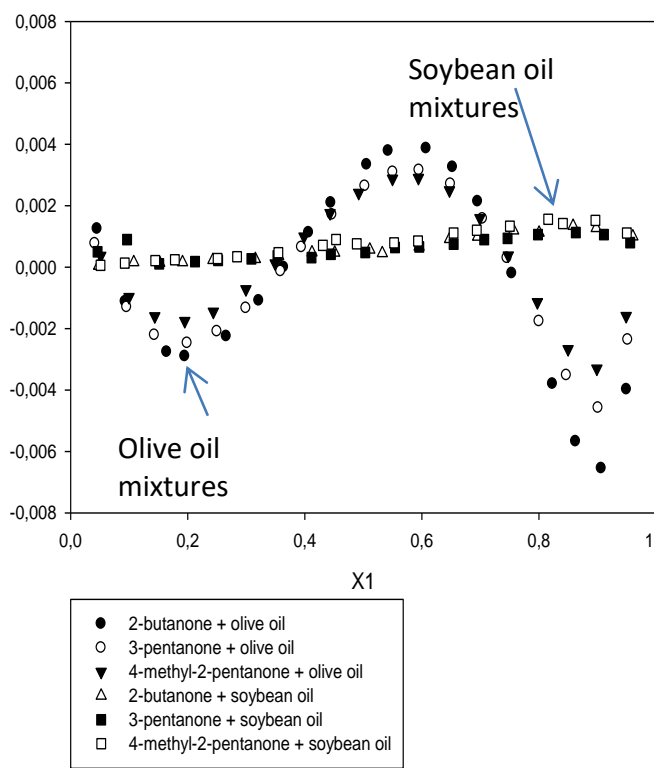

FIGURE 9 Deviation of refractive indices for all binary mixtures at $298.15 \mathrm{~K}$ using Lorentz-Lorenz mixing rule.

\section{Conclusions}

It is of wide known that thermodynamic magnitudes govern the behaviour of mixing chemicals involved into chemical processes. High quality values of basic thermodynamic properties can be applied to model and design industrial devices and transference processes in chemical industry. Density and refractive index has been a subject of coreinterest during the recent past years due to measurements of these magnitudes in solutions formed by liquid components show the degree of deviation from ideal trend at any range of operation condition. These deviations have been used to gain insight into liquid nature and degree of molecularinteractions among the enclosed components. Accurate data of density and refractive index as a function of composition and temperature/pressure help to understand the nature of the individual chemicals and molecular interactions in complex systems and extreme operational conditions.For the design of winterization equipment and optimization of the operational 
parameters into edible oil processes, it is necessary to dispose of adequate thermodynamic data, as well as, appropriate models for estimation, modeling and simulation. The present work gathers density and refractive index on mixing as a function of concentration for binary systems of ketones (2butanone, 3-pentanone and 4-methyl-2-pentanone) with (olive or soybean) oils from 283.15 to $298.15 \mathrm{~K}$. Increasingly, industrial process design involves the use of computer aided procedures. The physical property packages used in chemical simulators typically rely on generalized equations for predicting properties as a function of temperature, pressure, etc. Despite the success developing several procedures of density and refractive index estimation for pure compounds or mixtures, only a few of them may be of real application for mixtures of chemicals of non-ideal trend or high molar mass as oils into solvents.Different theoretical models were applied to analyze their capability in terms of estimation of the studied properties as a function of composition and temperature. A simplification of the Nasrifar-Moshfeghian liquid density correlation (MNM method), theHalvorsen equation of state and a modified Heller equation (MHE) for density and a collection of semiempirical rules for refractive index on mixing were tested to analyze their capability in terms of estimation of the studied properties as a function of composition and temperature. These models gathered, at least, qualitative agreement in prediction, despite the strong non-ideality of these mixtures and the use of group contribution methods for critical point predictions for the studied edible oils.

\section{Acknowledgment}

The authors would like to acknowledge the CNPq Conselho Nacional de DesenvolvimentoCientífico e Tecnológicofor the DT grant (Bolsa de DesenvolvimentoTecnologico)(ChamadaCNPq $\quad n^{\circ}$ $29 / 2019$, processo $313601 / 2019-4)$ for support in developing this research.

\section{Appendix. Supplementary data}

Supplementary data related with this article should be found in the online version.

\section{References}

[1]Farrall, A.W., 1976. Food engineering systems, The AVI Pub. Co. Inc. Westport

[2]Swern, D., 1979. Bailey's industrial oil and fat products, 4th ed., IntersciencePublishers, John Wiley \& Sons.

[3] Charm, S.E., 1981. The fundamentals of food engineering, The AVI Pub. Co. Inc..

[4] Singh, R.P., Heldman, D.R., 1984. Introduction to food engineering, Academic Press, Inc..

[5] Prentice, J.H., 1984. Measurements in the rheology of food stuffs, Elsevier Applied Science Pub. Ltd..

[6] Le Maguer, M., Jelen, P., 1986. Food engineering and process applications, Elsevier Applied Science Pub. Ltd..

[7] Rao, M.A., Rizvi, S.S.H., 1986. Engineering properties of foods, Marcel Dekker Inc.
[8] Lewis, M.J., 1987. Physical properties of foods and food processing systems, Ellis Herwood Ltd..

[9] Abe, Y., 1988. Handbook of fats and oils, Saiwai Shobo Co. Ltd..

[10] Lawson, H. W., 1995. Food oils and fats: Technology, utilization and nutrition. Springer Science \& Business Media.

[11]Widlak, N., 1999. Physical properties of fats, oils and emulsifiers, AOCS Press.

[12] Gunstone, F.D., 2002. Vegetable oils in food technology: composition, properties and uses, Blackwell Science Ltd..

[13] Akoh, C. C., 2005. Handbook of functional lipids, CRC Tayor\& Francis.

[14] Gunstone, F. D., Harwood, J. L., Dijkstra, A. J., 2007. The lipid handbook. CRC Press.

[15] O’Brien, R. D., 2008. Fats and oils: Formulating and processing for applications. CRC Press.

[16] Aparicio, R., Harwood, J., 2013. Handbook of olive oil: Analysis and properties. Springer.

[17] Peri, C., 2014. The extra-virgin olive oil. Wiley Blackwell.

[18] Bockisch, M., 2015. Fats and oils handbook. Elsevier.

[19] C. Gonzalez, J.M. Resa, A. Ruiz, and J.I. Gutierrez, "Densities of mixtures containing n-alkanes with sunflower seed oil at different temperatures," J.Chem.Eng.Data, 41, 796-798, 1996.

[20] C. Gonzalez, M. Iglesias, J. Lanz, J.M. Resa, "Temperature dependence of excess molar volumes in (n-alkane (C6-C9) or alcohol (C2-C4)) + olive oil mixtures," Thermochim. Acta, 328, 277-296, 1999.

[21] C. Gonzalez, J.M. Resa, J. Lanz, "Excess volumes of binary mixtures that contain olive oil with alkyl and vinyl acetates,"JAOCS. 77, 985-990, 2000.

[22]C. Gonzalez, M. Iglesias, J.Lanz, G. Marino, B. Orge, J.M. Resa, "Temperature influence on refractive indices and isentropic compressibilities of alcohol $\left(\mathrm{C}_{2}-\mathrm{C}_{4}\right)+$ olive oil mixtures," J. Food Engng., 50, 029-040, 2001.

[23] J.M. Resa, C. Gonzalez, M.A. Fanega, S. Ortiz de Landaluce, J. Lanz, "Enthalpies of mixing, heat capacities, and viscosities of alcohol $\left(\mathrm{C}_{1}-\mathrm{C}_{4}\right)+$ olive oil mixtures at 298.15K," J. Food Eng., 51, 113-118, 2002.

[24] C. Gonzalez, J.M. Resa, J. Lanz, M. Iglesias, J.M. Goenaga, "Measurements of density and refractive index of soybean oil + short aliphatic alcohols," Int. J. Thermophys. 27, 1463-1481, 2006.

[25]C. Gonzalez, J.M. Resa, J. Lanz, M. Iglesias, "Intermolecular interactions insoybean oil + different organic solvents by ultrasonic velocity measurements," J. Food Eng., 77, 152-161, 2006.

[26] C. Gonzalez, J.M. Resa, R.G. Concha, J.M. Goenaga, "Enthalpies of mixing and heat capacities of mixtures containing acetates and ketones with corn oil at 25 C'J. Food Eng. 79, 1104-1109, 2007.

[27] R. S. Andrade, G. A. Ferreira, D. Camargo, M. Iglesias, "Thermodynamic properties of palm oil (Elaeisguineensis) and evening primrose seed oil (Oenothera biennis) as a function of temperature," 
World Wide Journal of Multidisciplinar Research and Development, 2, 038-043, 2016.

[28] R.S. Andrade, M. Matos, C. Gonzalez, M. Iglesias, "Temperature influence on thermodynamic properties of argan (Argania spinosa), neem (Azadirachtaindica) and common walnut (Juglans Regia L.) oils," Int. J. Eng. Res.\& Tech., 5(10), 160-167, 2016.

[29] F. Tanajura, R. S. Andrade, C. Gonzalez, M. Iglesias, "Thermodynamic properties of peanut, canola and rosamosqueta oils,“ Elixir Int. J., 101, 43587-43592, 2016.

[30] R. S. Andrade, A. Andrade, A. A. Simões, M. Iglesias, "Thermodynamic study of jojoba (SimmondsiaChinensis) oil as a function of temperature," Int. J. Engng. Res. \& Tech., 6(10), 245250, 2017.

[31] C. Gonzalez, J. Lanz, R.S. Andrade, M. Iglesias, "Mixing properties of (n-alkanes or esters) + olive oil at different temperatures," Int. J. Thermodyn., 00, 000-000, 2020 (submitted for publication).

[32] Kh. Nasrifar, Sh. Avatollahi, M. Moshfeghian, "An extended saturated liquid density equation"Fluid Phase Equilib. 166, 163-181, 1999.

[33] A. Mchaweh, A. Alsaygh, K. Nasrifar, M. Moshfeghian, "A simplified method for calculating saturated liquid densities," Fluid Phase Equilib., 224, 157-167, 2004.

[34] M. Iglesias, B. Orge, J. Tojo, "Refractive indices and densities of the ternary mixtures acetone + methanol + water and acetone + methanol + 1-butanol at 298.15 K," Fluid Phase Equilib., 126(2), 203-223, 1996.

[35] J.D. Halvorsen, W.C. Mammel, and L.D. Clements, "Density estimation for fatty acids and vegetable oils based on their fatty acid composition, "J. Am. Oil Chem. Soc., 70, 875-880, 1993.

[36] H. G. Rackett, "Equation of state for saturated liquids," J. Chem. Eng. Data, 15, 514-517, 1970.

[37] C. F. Spencer, R. P. Danner, "Improved equation for prediction of saturated liquid density," J. Chem. Eng. Data, 17(2), 236-241, 1972.

[38] Madrid A., CenzanoY.,VicentJ. M., Manual de Aceites y Grasas Comestibles. AMV Ediciones, Madrid, 1997.

[39]TRC Thermodynamic Tables, Non-hydrocarbon, Thermodynamic Research Center, Texas AM University, College Station, Texas (1996).

[40] Riddick, J. A., Bunger, W. B., Sakano, T. K., 1986. Organic solvents. Physical properties and methods of purification, John Willey \& Sons.

[41] J. D., Alvarado, "Propiedades mecánicas de aceites y grasas vegetales," Grasas y Aceites. 46, 264-269, 1995.

[42] Mehlenbacher,V.G. 1960. Analysis of fats and oils, The Garrand Press.

[43] Physical and Chemical Characteristics of Oils, Fats, and Waxes, AOCS, 2013.

[44] Poling, B.E.,Prausnitz, J.M., O’Connell, J. P.,2001. The Properties of Gases and Liquids, McGraw-Hill.
[45] R. Gani, L. Constatinou, "Molecular structure based estimation of properties for process design," Fluid Phase Equilib. 116, 75-86, 1996.

[46] DIADEM PUBLIC 1.2.0, 2000. The DIPPR Information and Data Evaluation Manager.

[47] CHEMÉO Database. Available: www.chemeo.com (accessed in May. 18, 2020). 